\title{
Supporting Legal Requirements in the Design of Public Processes
}

\author{
Amina Cherouana and Latifa Mahdaoui \\ University of Sciences and Technology Houari Boumediene (USTHB), \\ Algiers Algeria \\ \{acherouana, Imahdaoui\}@usthb.dz
}

\begin{abstract}
Nowadays, business processes have become an ubiquitous part in public institutions, and the success of an e-government system depends largely on their effectiveness. However, despite the large number of techniques and technologies that are successfully used in the private sector, these cannot be transferred directly to public institutions without taking into account the strongly hierarchical nature and the rigorous legal basis on which public processes are based. This work presents an approach allowing the consideration of the legal requirements during the public processes design. Its main particularity is that these requirements are encapsulated using a legal features model supporting a formal semantic. This one prevents the violation of legal requirements and ensures that the processes evolution will in compliance with them.

Keywords: E-government, Information and Communication Technologies (ICT), Business Process Management (BPM), Public Process Design, Legal Requirements.
\end{abstract}

\section{Introduction}

E-government is a phenomenon of an era in which e-business is becoming vital in both the private and the public sector. It is composed of a set of administrative processes (considered as business processes) whose mission is to serve citizens or businesses.

Indeed, the concept of business process has become an ubiquitous part in public institutions, and the success of an e-government system depends largely on their effectiveness. Consequently, the enormous and the spectacular benefits achieved in the industry and the private sector through the adoption of Business Process Management (BPM) haven't been without impact on public institutions. Let's note that the BPM is a process-centric approach which includes concepts, methods and technologies to support the design, administration, configuration, enactment, and analysis of business processes.

However, despite the large number of techniques and technologies that are successfully used in the private sector, these cannot be transferred directly to public institutions without taking into account the strongly hierarchical nature and the rigorous legal basis on which public processes are based. The Government Process Management (GPM) is the thinking that derives from the application of BPM for public processes [18][19][20]. 
The process models in a such context are characterized by a set of rules, principles and specific models, collectively here referred to as legal requirements.

This work focuses on the design of public processes. Hence, the main problem in this context is to say: 'how to ensure that the designed public process models are on conformity with the legal framework governing public institutions?'. Under this issue, this paper proposes an approach allowing the consideration of the legal requirements during the public processes design. Let's specify that the legal requirements are mentioned in the law and the set of legal texts which constitute a source of valuable and incontrovertible knowledge.

The main particularity of this approach is that the legal requirements are encapsulated using a legal features model supporting a formal semantic. This semantic prevents the violation of legal requirements and ensures that the processes evolution is in compliance with them. In addition, the legal features model constitutes the core from which the first global models of public processes will be derived. These ones are, then, enriched with organizational aspects undescribed in the law and specific to each institution. Let's note that the legal features model is implemented using the Ontology Web Language (OWL) based on the Description Logics (DL) and the first, as well as the final, models of public processes are generated using the Workflow Nets formalism (WfN).

The remaining of this paper is structured as follow:

- Several research works can be inscribed in the same category as this work and try to propose solutions for the consideration of the legal requirements. A classification of these works and our positioning regarding these ones are made in the second section.

- The presentations of the proposed approach, as well as the description of its component intentions and strategies are made in the third section.

- This approach was tested and validated with the cooperation of an annex of Algerian Fiscal Administration. An overview of the results is presented in the fourth section.

\section{Related Works}

The legal requirements are mentioned in the law which includes the set of decrees and legal texts that are associated to each public institution. These contain the set of components, management rules and instructions regarding a public administrative procedure [5][6][20]. They also regulate strictly how to create a certain output [4].

Consequently, the consideration of legal requirements characterizing public institutions has become a major preoccupation in several research works. A thorough study of these has allowed us to classify them into three different orientations as shown below: 
Table 1. Related Works Classification

\begin{tabular}{|l|l|l|}
\hline Orientation & Description & $\begin{array}{l}\text { Examples } \\
\text { of related works }\end{array}$ \\
\hline Normative Studies & $\begin{array}{l}\text { Refers to the works that focus on the description of legal re- } \\
\text { quirements as a distinctive aspect of public institutions, and } \\
\text { the demonstration of the importance of their consideration in \& al., 2009 [1] } \\
\text { the proposal of any IT solution }\end{array}$ & $\begin{array}{l}\text { Saarenpaa \& al.,2003 [2] } \\
\text { Lenk, } 1997 \text { [3] }\end{array}$ \\
\hline $\begin{array}{l}\text { Methodologies } \\
\text { and tools }\end{array}$ & $\begin{array}{l}\text { Refers to the works that attempt to develop appropriate } \\
\text { methodologies, tools and techniques to the support of legal } \\
\text { requirements. They also covers the works that propose spe- } \\
\text { cific conceptual and methodological frameworks }\end{array}$ & $\begin{array}{l}\text { Ciaghi \& al., 2011 [4] } \\
\text { Alpar \& al., 2005 [6] }\end{array}$ \\
\hline $\begin{array}{l}\text { Compliance assessment } \\
\text { and verification }\end{array}$ & $\begin{array}{l}\text { Refers to the works whose purpose is the assessment of im- } \\
\text { plementation results and the verification of the compliance } \\
\text { degree with the legal aspect }\end{array}$ & $\begin{array}{l}\text { Amboala \& al., 2010 [7] } \\
\text { Wastell \& al., 2001 [8] } \\
\text { Zuo \& al., 2010 [9] }\end{array}$ \\
\hline
\end{tabular}

This work belongs to the second category. Among works explored in this category are that of [4] who combine the principle of Business Process Reengineering (BPR) with a goal-oriented framework in order to analyze and to model the law. The emerged processes are then visualized using a subset of UML diagrams. In the same sense, there exists the works of [5] which propose framework for extraction and feeding processes from legal texts. The framework applies pipes and filters architecture and uses NLP tools to perform information extraction steps. A third example is that of [6] who focus on the problem of legal requirements modeling using the EPC language (Event-Driven Process Chain). They propose, then, an extension of the graphical notations of this language very responded in the business field.

The main particularity of the solution developed comes to the use of a formal semantic for a legal requirements support. In the following, a detailed description of the proposed solution and its intentions is made.

\section{Approach Description}

As mentioned above, the main concern of this work is the consideration of the legal requirements during the design of public processes. Therefore, the proposed solution consists, firstly, to encapsulate them into a legal features model supporting a formal semantic. This latter is represented using an ontological framework devoted to the semantic conception and implementation of public processes. It allows preventing the violation of legal requirements and ensuring that the processes evolution will in compliance with them.

The resulting legal features model constitutes the core from which the first global models of public processes must be derived. At this level, passage rules have been defined and implemented to ensure the automatic passage. These models are, then, enriched with organizational aspects undescribed in the law and specific to each institution in order to generate public process models. The figure.1 shows in detail the different intentions and strategies of the proposed approach. 


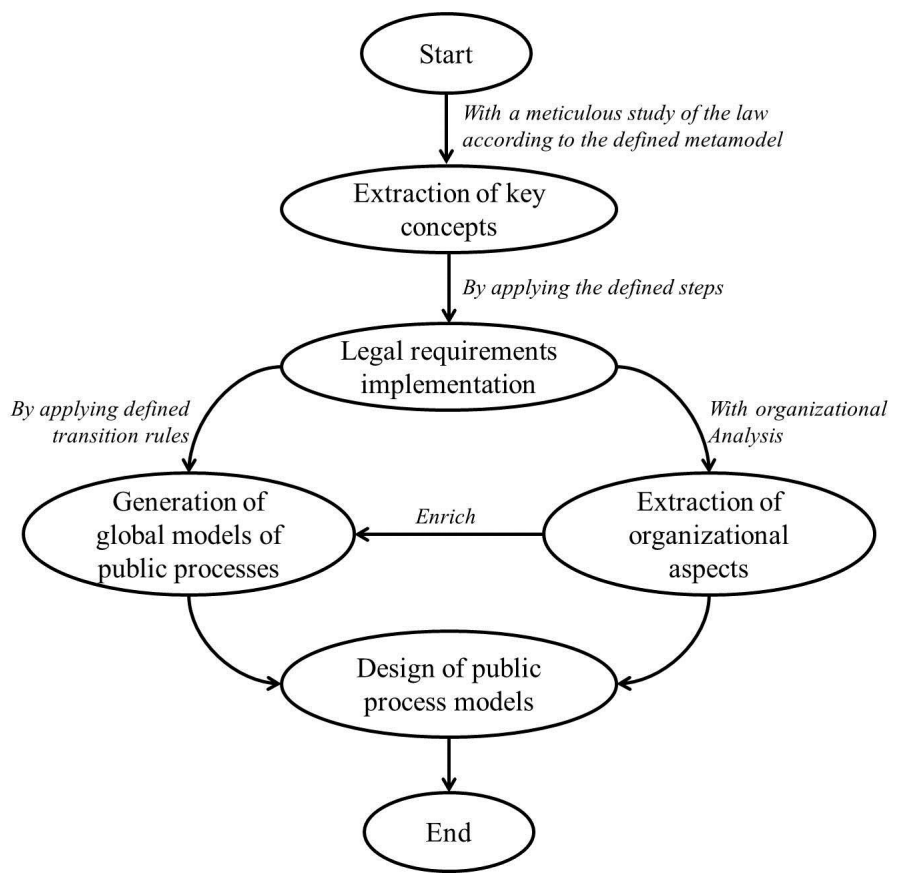

Fig. 1. Approach for Public Process Design

We use the MAP model [25] in order to represent clearly the approach phases, as well as the interrelations between them. The map is represented using an oriented and a labeled graph. The nodes represent intentions and the links represent strategies.

\subsection{Extraction of Key concepts}

The first intention to achieve is the extraction of the key concepts which will be used in the legal requirements implementation intention. Hence, the starting point of this approach is a "meticulous study of the law" governing the targeted institution.

Several types of law exist, therefore it is important to operate a selection procedure and keep only those which provide information and knowledge that can be instantiated in the process (e.g. executive decrees and procedural decrees).

We have developed a law meta-model below (Figure 2) to describe the main concepts to be extracted. It covers all components that must be addressed in public processes design. Let's note that a key concept must not be questioned during the design process: it is necessary but not sufficient. A law is structured as several articles. It represents the primordial source providing the key concepts grouped in the following dimensions: 


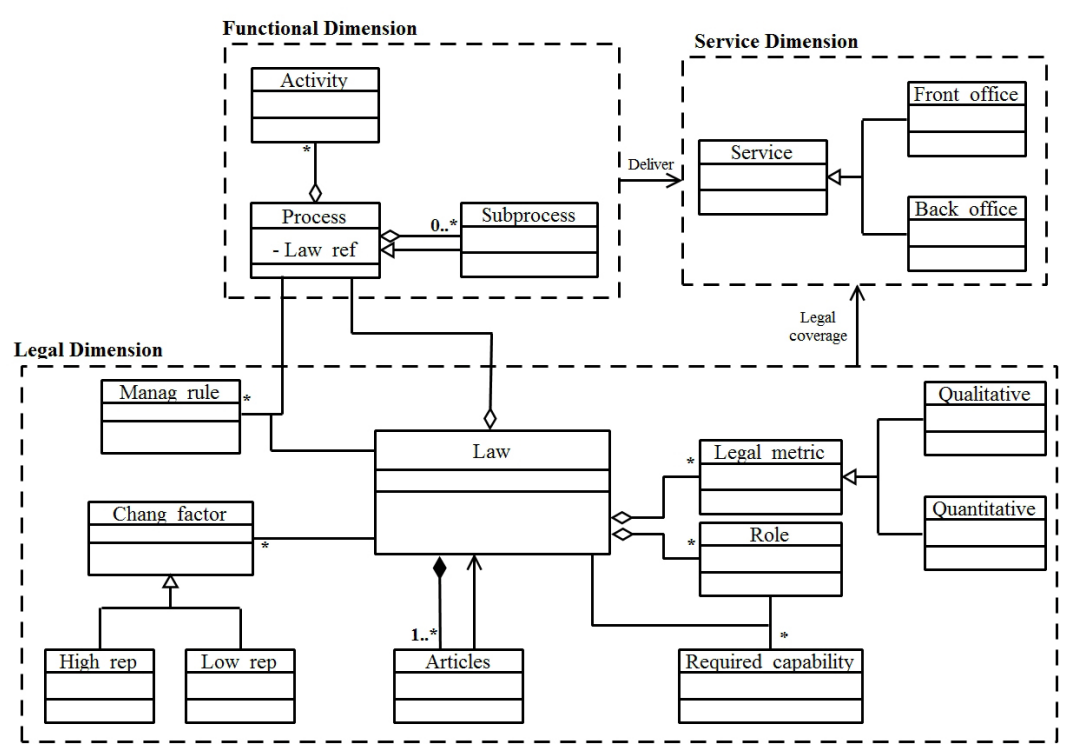

Fig. 2. Law Meta-Model for Public Process Design

\subsection{Legal Requirements Implementation}

Once the key concepts extraction was established, we pass to the implementation of the legal requirements governing the public processes. The main objective is to encapsulate the legal requirements through assets serving as the basis for the prevention of their violation. This one includes the definition of process parts, the structural relationships, as well as the description of dependencies between processes. The three "defined steps" to achieve this intention are shown in the figure 3 :

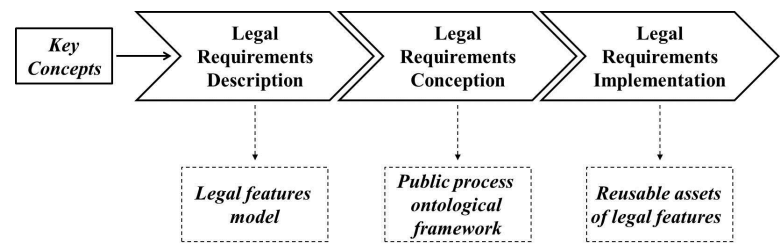

Fig. 3. Defined Steps for Legal Requirements Implementation

\section{Legal requirements description.}

The objective of this phase is the generation of legal features model encapsulating the legal requirements. This phase uses as input the key concepts derived from the previous intention.

We adopt the feature model of Feature-Oriented Domain Analysis method [10]. This model is an explicit representation as a tree where nodes constitute the set of char- 
acteristics and the arcs specify the relationship between them. Let's specify that some features may have variations to choose and which will be resolved using the description logic (DL) during the implementation of legal requirements.

\section{Legal requirements conception.}

It essentially comprises the construction of public processes ontology through a specific ontological framework. Indeed, we have defined a specific ontological framework for the semantic representation of public processes based on the legal features model. It is composed of two levels: (1) ontological framework associated to a public process, and (2) ontological framework associated to a public activity.

We have used the method of Uschold and King [12] who propose a method for enterprise's ontology construction. This latter is a two-level ontology, where the highlevel is used to describe the domain concepts which, for their part, are placed in the second level [13][14]. We have selected the following corpus to describe the high-level of our ontology: Entity, Relationship, Role, State-of-affairs and Time. These concepts are required to model any public process.

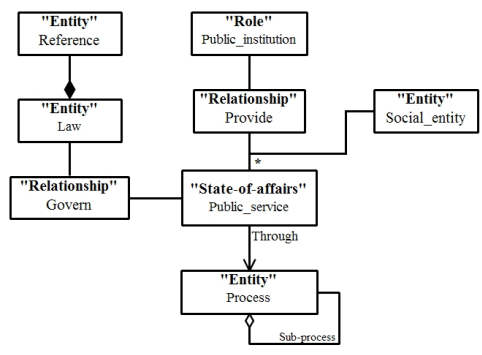

Fig. 4. Ontological Framework for a Public Process

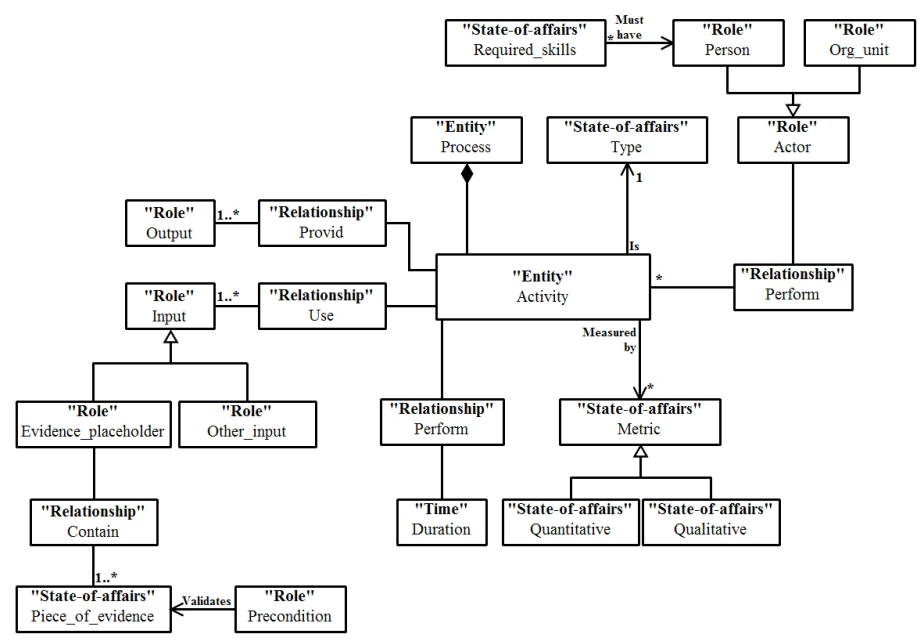

Fig. 5. Ontological Framework for a Public Activity 


\section{Legal requirements implementation.}

Legal requirements implementation is made with Ontology Web Language (OWL) based on the Description Logics (DL). Its main objective is the creation of assets that provide a basis from which the public process models will be derived.

This step includes also the configuration of the processes from the static variations points using a set of description logic axioms. This one favors the reuse of assets [15][16], prevent the violation of dependencies between variants of the features model by treating characteristics as components and dependencies as constraints [17].

\subsection{Generation of Global Models of Public Processes}

The purpose of this intention is the generation of the first global models as a Workflow Nets. Thus, a transformation rules allowing the passage from legal features model to Workflow Nets has been defined. For space reasons, these rules can't be presented in this paper. However, an example of the resulting global model will be presented in the relevant section in the case study.

This phase includes also the definition of execution order and the configuration of dynamic variations points. At this level, it is not possible to add behavior that has not been modeled beforehand and therefore not described in the law. Thus, all possible behaviors described in the law must appear in the resulting model. To solve this problem, we have done recourse to the approach proposed by Gottschalk \& al. These authors have developed a configuration approach which is based on the restriction of the behavior for the Workflow Nets [22][23].

\subsection{Extraction of Organizational Aspects}

This intention covers mainly the: (1) identification of quick gains by identifying the flow in accordance with law, (2) collecting metrics of the current processes which allows, on one hand, to enrich those described in the law and produce an analytical view of the organization, and on the other hand, to establish a baseline for measurement and improvement of future processes, (3) extraction of actors with their appropriate skills in order to identify those able to occupy the roles extracted from the law, and to identify the need to improve capacity or to define new roles [20][21].

\subsection{Design of Public Process Models}

This is the intention where the public process models conform to the law are delivered. It comprises the necessary steps to transform the global dynamic models to the implementable models. It is during this phase where the integration of the organizational aspect is made. This last consists to define new activities/additional processes, new options and alternatives for processes within the project. It also includes the description of created or redefined jobs, the assignments of roles according to their capacity, as well as defining of business and managerial personnel with their job objectives. The manner in which their performance will be measured and managed is also changed or developed. 


\section{Case study: Algerian Fiscal Administration}

The Algerian fiscal administration is a public institution responsible for establishing the tax base, its perception and its control. It belongs to the category G2B (Government to Business), which imposed the study of the different stakeholders, as well as their rights and obligations towards the fiscal administration. Three categories of taxpayers are distinguished: (1) physical person, (2) capital company, and (3) foreign company which is divided to those installed and others not installed. For the test and the validation of this approach we have cooperate with the local Annex of Algiers.

\subsection{Extraction of Key concepts}

A set of decrees (between executive and procedural) were selected to analyze and to extract legal requirements related to the tax regime on which taxpayers are subject (ex. Decree $\mathrm{N}^{\circ}$. 96-31, Decree $\mathrm{N}^{\circ}$. 08-98, Decree $\mathrm{N}^{\circ}$. 01-353, etc) [26]. The analysis of these documents has allowed identifying more than twenty processes each having a set of associated key concepts. These are conforming to the key concepts described in the law meta-model (Figure 2).

\subsection{Legal Requirements Implementation}

\section{Legal requirements description.}

A fragment of the resulting legal features model related to the Algerian Fiscal Administration is shown in the following figure:

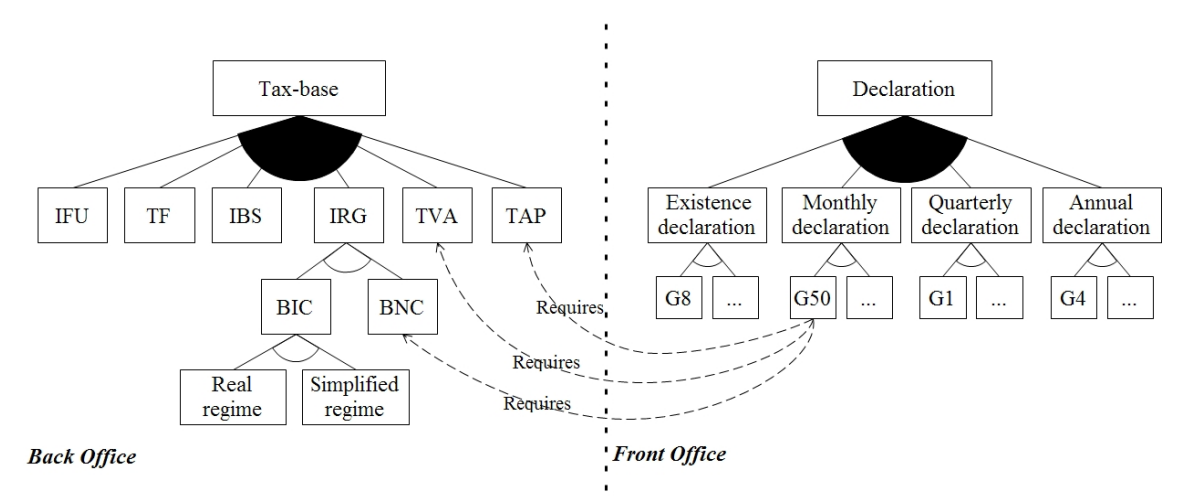

Fig. 6. Fragment of Legal Features Model of the Algerian Fiscal Administration

The back office represents the set of internal processes of the fiscal administration. For example, the global process "Tax-base", is composed of all taxable procedures described in the law (IFU, TF...). The front office represents the set of provided services to the different taxpayers. For example, "Declaration" is composed of all statements that the concerned must declare (Existence declaration, Monthly declaration...). 


\section{Legal requirements conception.}

The purpose of this phase is to build public processes ontology. It is made from the high-level ontology (Figure 4 and Figure 5). Let's note that each public process and its component activities must be designed and then implemented. An example of public process ontology (the Monthly declaration process) is shown in the figure7.

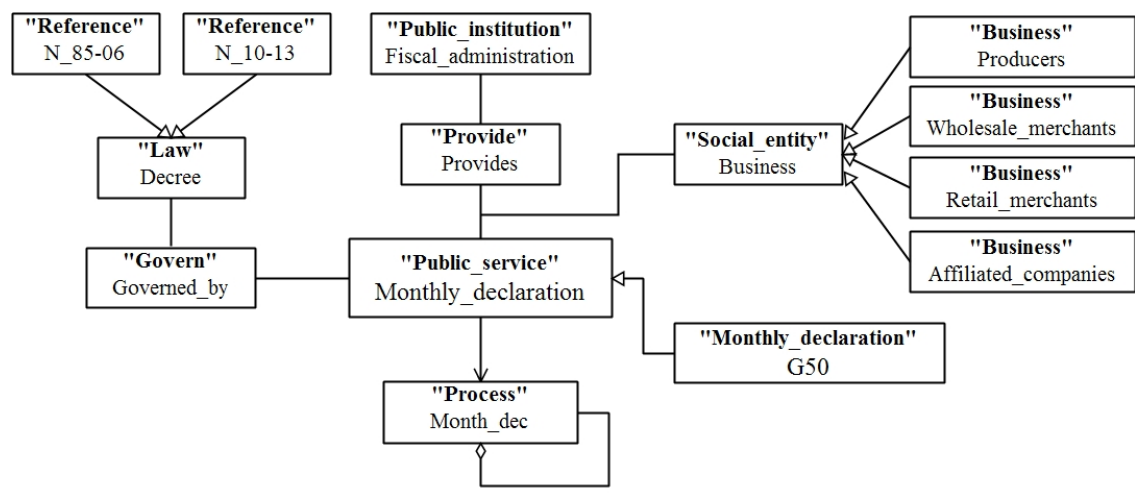

Fig. 7. Ontology Overview of the "Monthly_declaration" Process

\section{Legal requirements implementation.}

The implementation of the legal requirements starts with the implementation of the highlevel ontology with its components concepts and dependencies between them. The latter is, subsequently, imported to create the assets of different legal features. Remember that a set of axioms is also implemented in this phase. In addition, the assets consistency and the concepts classification and positioning have been checked using a specific reasoner, before their use in the next intention.

\subsection{Generation of Global Models of Public Processes}

This phase must be initiated by the generation of the first global models of public processes by applying defined rules, and defining the execution order of the extracted components. As example, the application of the defined rules on the back-office gives the following model: 


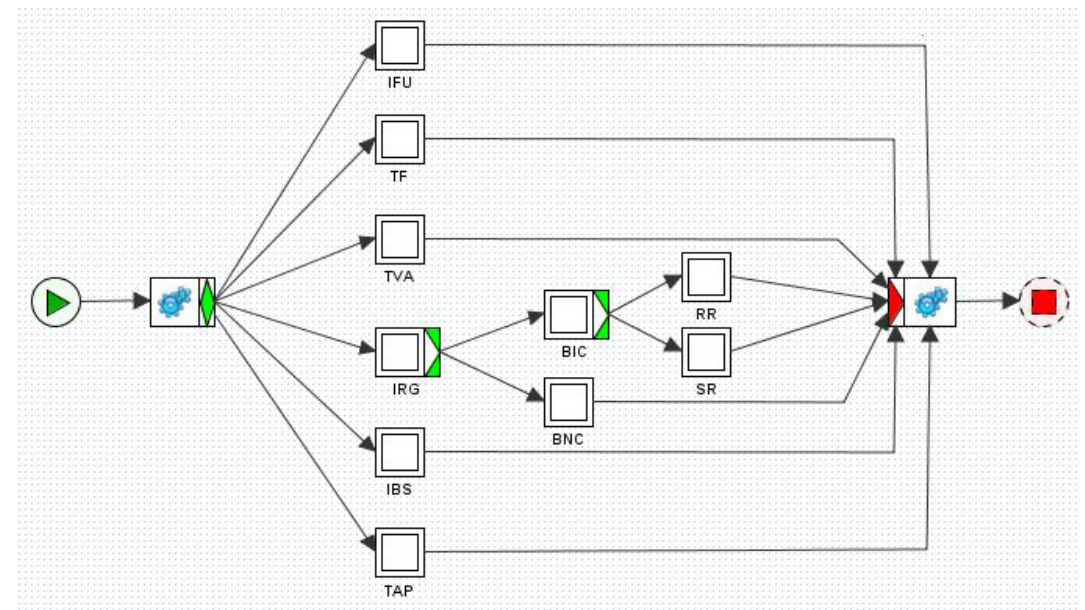

Fig. 8. Example of a Global Public Process Model

Let's recall that the resolution from the dynamic variation points was also made according to the mentioned approach [22][23].

\subsection{Extraction of Organizational Aspects}

This phase begins with the representation of current operational processes with BPMN notation. BPMN is located at the analysis level. It was introduced to provide a graphical notation easy to understand. These current models are, subsequently, analyzed and confronted with implemented assets.

This analysis allowed extracting several flows, activities, qualitative/ quantitative operational metrics and identifying needs to define new alternatives in the next phase. For extracted roles, establishing the matrix of capabilities [24] has provided useful information on current and future skills needs.

\subsection{Design of Public Process Models}

An overview of public process model "IFU" is shown in Figure 9. The development of this model is made by integrating the organizational aspect delimited by the constraints of the implemented assets (ex. the sub-processes must be triggered by the tax administration, the taxpayer has 30 days to express its decision, etc.) and other issues from the previous phase (ex. time allowed for the tax inspector in order to treat against-proposal). 


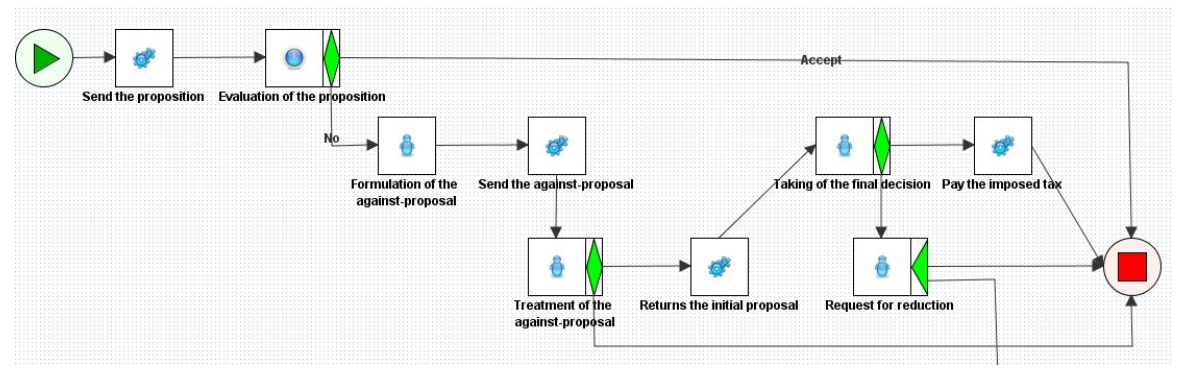

Fig. 9. An Overview of Resulting Public Process Model

\section{Conclusion}

The objective of efficiency and effectiveness improvement of the e-government is a primordial problem. The processes of such system must obey to certain requirements of process models described in the law and the set of legal texts. For this fact, the internal processes are partially ruled and governed by a legal framework.

We have focused in this work to propose a design approach allowing the consideration and the support of the legal requirements governing a given public institution. The main particularity of this approach is that the legal requirements are encapsulated using a features model supporting a formal semantic. This last is represented using an ontological framework devoted to the semantic conception and implementation of public processes.

Several aspects can also be developed in order to evolve this approach. We focus now on the first intention and we try to develop a cooperative platform for the meticulous study of the law strategy in accordance with the law meta-model presented previously.

\section{References}

1. L. Ximeng, Research on E-government Initiatives and Enabling IT, PhD thesis, University of Hong Kong, 2009.

2. A. Saarenpaa, A Legal Framework for E-Government, EGOV'2003, LNCS 2739, pp. 377-384, 2003.

3. K. Lenk, Business process reengineering in the public sector: opportunities and risks, Beyond BPR in Public Administration: an institutional transformation in an information age, pp. 151165, IOS Press, 1997.

4. A. Ciaghi et A. Villa_orita, Improving Public Administrations via Law Modeling and BPR, AFRICOM, 2011.

5. P. Schumacher, M. Minor, and E. Schulte-Zurhausen, Extracting and enriching workflows from text, 14th International Conference on Information Reuse and Integration (IRI), IEEE, August 2013.

6. P. Alpar, and S. Olbrich, Legal requirements and modelling of processes in e-government, Electronic Journal of e-Government, vol. 3, no. 3, p. 107-116, 2005. 
7. T. Amboala, M. Japang, J. Likoh, M. Yuszreen, Business Process Reengineering In Labuan Fire Services Operations: A Case Study, Labuan e-Journal of Muamalat and Society LJMS - Special Issue, Vol. 4, 2010, pp. 14-25, 2010.

8. D. Graham Wastell, P. Kawalek et M. Willetts, Designing alignment and improvising change: Experiences in the public sector using the SPRINT methodology, ECIS 2001: 1125-1136, 2001.

9. L. Zuo and Y. Liu, Notice of Retraction Organizational Change Pattern Based on Business Process Reengineering, International Conference on E-Business and E-Government, 2010.

10. K. Kang, S. Cohen, J. Hess, W. Novak, and A. Peterson, Feature-Oriented Domain Analysis (FODA) Feasibility Study, Technical Report CMU/SEI-90-TR-21, SEI. Carnegie Mellon University, Pittsburgh, Pennsylvania, 1990.

11. T. Thum, K. Kastnery, S. Erdwegy, and N. Siegmund, Abstract Features in Feature Modeling,15th International Software Product Line Conference, 2011.

12. M. Uschold, M. King, S. Moralee and Y. Zorgios, The enterprise ontology. Knowledge Engineering Review', 13(1), 31-90, 1996.

13. L. Penicina, L. Choosing a BPMN 2.0 Compatible Upper Ontology, eKNOW 2013 : The Fifth International Conference on Information, Process, and Knowledge Management.

14. S. K. Semy, M. K. Pulvermacher, and L. J. Obrst, Toward the Use of an Upper Ontology for U . S . Government and U . S . Military Domains : An Evaluation, Corporate Head-quarters Bedford, Massachusetts, 2004.

15. Y. Huang, and S. Key, Ontology-Based Configuration for Service-Based Business Process Model, IEEE International Conference on Services Computing (SCC), 2013.

16. M. Döhring, A. Reijers, and S. Smirnov, Configuration vs. adaptation for business process variant maintenance: An empirical study, Information System Journal - Elsevier, Vol 39, pp. 108-133, 2013.

17. S. Mafazi, W. Mayer, G. Grossmann, and M. Stumptner, A Knowledge-based Approach to the Configuration of Business Process Model Abstractions, Journal of Knowledge-Based Configuration- Survey and Future Directions, Vol. 15, pp 47-66, 2012.

18. N. Zhang and X. Hou, Government Process Management under electronic government and its application, in International Conference on E-Business and E-Government (ICEE), 2011, p. 1-4.

19. X. Xuefang, Study of government information construction based on BPR, in International Colloquium on Computing, Communication, Control, and Management, CCCM'2009. vol. 1, p. 318-320, 2009.

20. A. Cherouana, and L. Mahdaoui, Towards a methodological framework for the Government Process Management, In International Conference on Research Challenges in Information Science (RCIS), 2012, Valencia, Spain.

21. A. Cherouana, and L. Mahdaoui, Study of OSSAD applicability in a GPM framework, International Conference on Electronic Governance (ICEGOV), 2013, Seoul, Republic of Korea.

22. F. Gottschalk, W. Van der Aalst, M. Jansen-Vullers, and L.R Marcello, Configurable Workflow Models, Int. J. Cooperative Inf. Syst. 17(2): 177-221 (2008).

23. F. Gottschalk, A. Teun, C. Wagemakers, H. Monique, W. Van der Aalst, Configurable Process Models: Experiences from a Municipality Case Study, CAiSE 2009: 486-500.

24. J. Jeston, and J. Nelis, Manage by Process - A Roadmap to Sustainable Business Process Management, Published by Elsevier Ltd, 2008.

25. C. Rolland, N. Prakash, A. Benjamin, A Multi-Model view of Process Modelling, Requirement Engineering, volume 4, 169-187, 1999.

26. Algerian Official Journal - JORA. Available: www.joradp.dz/. 